\title{
Derivation of the formyl-group oxygen of chlorophyll $b$ from molecular oxygen in greening leaves of a higher plant (Zea mays)
}

\author{
R.J. Porra* ${ }^{\mathrm{a} *}$ W. Schäfer ${ }^{\mathrm{b}}$, E. Cmiel ${ }^{\mathrm{c}}$, Ingrid Katheder ${ }^{\mathrm{a}}$ and H. Scheer ${ }^{\mathrm{a}}$ \\ a Botanisches Institut der Universität, W-8000 München 19, Germany, ${ }^{\mathrm{b}}$ Max-Planck-Institut für Biochemie, W-8033 Martinsried, \\ Germany and 'Institut für Physikalische Chemie. Technische Universität München, W-8046 Garching, Germany
}

Received 26 March 1993

Using mass spectroscopy, we demonstrate as much as $93 \%$ enrichment of the 7-formyl group oxygen of chlorophyll $b$ when dark-grown, etiolated maize leaves are greened under white light in the presence of ${ }^{18} \mathrm{O}_{2}$. This suggests that a mono-oxygenase is involved in the oxidation of its methyl group precursor. The concomitant enrichment of about $75 \%$ of the $13^{1}$-oxygen confirms the well-documented finding that this oxo group, in both chlorophyll $a$ and $b$, also arises from $\mathrm{O}_{2}$. High ${ }^{18} \mathrm{O}$ enrichment into the 7 -formyl oxygen relative to the substrate ${ }^{18} \mathrm{O}_{2}$ was achieved by optimization of the greening conditions in combination with a reductive extraction procedure. It indicates not only a single pathway for Chl $b$ formyl group formation, but also unequivocally demonstrates that molecular oxygen is the sole precursor of the 7 -formyl oxygen.

Biosynthesis; Photosynthesis; Chlorophyll $b ;{ }^{18}$ Oxygen; Isotope exchange: Reductıve extraction, Oxygenase

\section{INTRODUCTION}

Chl $b$, a light-harvesting antenna pigment in the photosynthetic apparatus of higher plants, green algae and prochlorophytes, differs from $\mathrm{Chl} a$ by possession of a formyl rather than a methyl group at C-7. The enzyme(s) involved in the oxidation of this methyl group to a formyl substituent have not been demonstrated in cell-free preparations, and the reaction mechanism is still unknown; indeed, the substrate of this oxidation is unclear and may be $\mathrm{Chl} a$, chlorophyllide $a$ or protochlorophyllide (for review see $[1,2]$ ).

In this paper, we investigate the proposition that the formation of the formyl group of Chl $b$ from a methyl substituent involves a mixed-function oxidase (monooxygenase) in which case the oxygen of the 7-formyl group would arise from molecular oxygen. Etiolated maize leaves were greened in the presence of ${ }^{18} \mathrm{O}_{2}$ and the chlorophylls extracted and examined by mass spectroscopy. $\mathrm{NaBH}_{4}$ was employed in the extraction to convert $\mathrm{Chl} b$ to [7-hydroxymethyl]-Chl $b$ to minimize

Correspondence address $\mathrm{H}$. Scheer, Botanisches Institut. Universitat München, Menzinger Str. 67, W-8000 München 19, Germany.

* Permanent address. CSIRO-Division of Plant Industry, GPO Box 1600, Canberra ACT 2601, Australia.

Abbreviations Chl, chlorophyll; DCMU, 3-(3,4-dichlorophenyl)-1,1dimethylurea: DEAE-cellulose, diethylamınoethyl-cellulose: FAB. fast-atom-bombardment; Phe, phaeophytin. The IUB-IUPAC approved numbering system for tetrapyrroles has been used with bracket [] nomenclature for substitutions. [7-hydroxymethyl]-Chl $b$ is identical to [7-hydroxymethyl]-Chl $a$ but will be referred to here as a Chl $b$ derivative to indicate its orign. loss of ${ }^{18} \mathrm{O}$ from the formyl group by reversible gem-diol (hydrate) formation with $\mathrm{H}_{2}{ }^{16} \mathrm{O}$ in the leaf. We demonstrate enrichments of approximately $93 \%$ of the 7 formyl oxygen of $\mathrm{Chl} b$ and of about $75 \%$ in the $13^{1}$ oxygen of both Chls $a$ and $b$. Recently, and independently, Schneegurt and Beale [3] reported $34 \%$ incorporation of label from ${ }^{18} \mathrm{O}_{2}$ into the formyl group of $\mathrm{Chl} b$ during greening of a mutant of the green alga, Chlorella vulgaris: precautions against gem-diol formation involved only rapid extraction at low temperature.

\section{EXPERIMENTAL}

2.1. Chemicals

${ }^{18} \mathrm{O}_{2}$ with $99.5 \%$ 1sotope enrichment was supplied by Novachem Pty. Ltd., Melbourne, Australia. DEAE-cellulose (DE 52), supplied by Whatman Laboratory Division, Maidstone, England, was treated and suspended in methanol [4]; the DEAE-cellulose was then equilibrated with $\mathrm{CHCl}_{3}$.

\subsection{Organisms. growth and greening condittons}

Three etiolated leaves, excised from 20-day-old, dark-grown maize seedlings (Zea mays hybrid var. Dekalb XL689) [5], were placed into each of six Thunberg tubes ( $50 \mathrm{ml}$ capacity) containing $2 \mathrm{ml}$ of deoxygenated water and filled with ${ }^{18} \mathrm{O}_{2}$ (approx. 70\%) and $\mathrm{O}_{2}$-free $\mathrm{N}_{2}$ (approx. $30 \%$ ) by standard vacuum-line techniques. The leaves in the sealed tubes were then greened by illumination with white light (50-60 $\mu \mathrm{E} \mathrm{m}^{-2} \cdot \mathrm{s}^{-1}$ ) for up to $26 \mathrm{~h}$ at $27^{\circ} \mathrm{C}$ (cf. [6])

2.3. Extraction and purification of chlorophylls from greened malze leaves

Leaves were extracted by grinding in a chlled mortar in a freshly prepared solution containing equimolar $(16.5 \mathrm{mM}) \mathrm{NaBH}_{4}$ and 8hydroxyquinoline. After centrifugation a clear methanohc supernatant containing Chl $a$ and [7-hydroxymethyl]-Chl $b$ with few chlorophyll by-products was obtained. The chlorophylls were transferred to diethylether before evaporating to dryness under reduced pressure. 
Table I

Theoretical intensity distribution of the clusters derived from the natural abundances of the $\mathrm{C}, \mathrm{H}, \mathrm{N}, \mathrm{O}$. and $\mathrm{Mg}$ isotopes

\begin{tabular}{|c|c|c|c|c|c|c|}
\hline & & $(\mathbf{M})^{+}$ & $(\mathrm{M}+1)^{+}$ & $(\mathrm{M}+2)^{+}$ & $(\mathrm{M}+3)^{+}$ & $(M+4)^{+}$ \\
\hline Chl $a$ & $\mathrm{C}_{55} \mathrm{H}_{72} \mathrm{~N}_{4} \mathrm{O}_{5} \mathrm{Mg}$ & 100.0 & 77.2 & 43.8 & 16.7 & 4.4 \\
\hline Phe $a$ & $\mathrm{C}_{55} \mathrm{H}_{74} \mathrm{~N}_{4} \mathrm{O}_{5}$ & 100.0 & 643 & 21.4 & 4.8 & 0.8 \\
\hline$\left[7-\mathrm{CH}_{2} \mathrm{OH}\right]-\mathrm{Chl} h$ & $\mathrm{C}_{55} \mathrm{H}_{72} \mathrm{~N}_{4} \mathrm{O}_{6} \mathrm{Mg}$ & 100.0 & 72.2 & 44.0 & 16.9 & 4.5 \\
\hline
\end{tabular}

The two major chlorophylls in the residue were separated on a column of $\mathrm{CHCl}_{3}$-equilibrated DEAE-cellulose developed with $\mathrm{CHCl}_{3}$. The eluant was monitored between $680-630 \mathrm{~nm}$ and $480-400 \mathrm{~nm}$ with a Shımadzu UV1202 spectrophotometer: the carotenoids were eluted first followed by Chl $a$ absorbing at 666 and $432 \mathrm{~nm}$. When [7-hydroxymethyl]-Chl $b$, absorbing at 659 and $434 \mathrm{~nm}$, began to clute, $2 \%$ $\mathrm{CH}_{3} \mathrm{OH}$ was added to the solvent to elute this derivative rapidly.

\subsection{Mass spectroscopy}

The Chl $a$ and [7-hydroxymethyl]-Chl $b$ were dissolved in methylene chloride and mass spectra recorded using liquid surface conization technique in a $m$-nitrobenzyl-alcohol matrix using a model MAT9000 mass spectrometer (Finnigan-MAT, Bremen) with a Caesium gun (20 $\mathrm{kV} . \approx 3 \mu \mathrm{A})$ and 1200 mass resolution After a survey in the exponential scan mode, 20-25 spectra of the molecular ion region in the linear scan mode were averaged $\mathrm{The}{ }^{18} \mathrm{O}$-isotope enrichment was calculated on the basis of the theoretical intensity distribution of the clusters derived from the natural abundances of the $\mathrm{C}, \mathrm{H}, \mathrm{N}, \mathrm{O}$ and $\mathrm{Mg}$ isotopes (Table I).

Furthermore, adjustment was made for the varying amounts of $\mathrm{M}^{+}$ and $\mathrm{MH}^{+}$ions arising from porphyrins and chlorins [7].

\section{RESULTS}

Extraction of leaves after greening with equimolar $\mathrm{NABH}_{4}$ and 8-hydroxyquinoline in methanol followed by DFAF-cellulose chromatography yielded $\mathrm{Chl} a$ and [7-hydroxymethyl]-Chl $b$ (see section 2): the 13'-oxo group was not reduced under these conditions. FABmass spectroscopy of the $\mathrm{Chl} a$ showed one ${ }^{18} \mathrm{O}$ label per tetrapyrrole molecule when the excised leaves were greened in an ${ }^{18} \mathrm{O}_{2}$-containing atmosphere (Table II). The isotope enrichments were 75 and $72 \%$ after 16 and $26 \mathrm{~h}$, respectively. Since $\mathrm{Chl} a$ is partially demetalated under FAB conditions, the Phe $a$ molecular ion was analysed in parallel: the slightly higher incorporation values (77 and $76 \%$ ) allow an estimate of the precision of the mass spectra analyses. This ${ }^{18} \mathrm{O}$ label is incorporated into the $13^{1}$-oxo group of $\mathrm{Chl} a$ by an oxygenase [8] during the obligatorily aerobic process of isocyclic ring formation [9].

The $\mathrm{Chl} b$ derivative contained two ${ }^{18} \mathrm{O}$ labels per tetrapyrrole molecule after incubation of leaves in the ${ }^{18} \mathrm{O}_{2}$-containing atmosphere: the first is again located in the $13^{\prime}$-oxo group and the second, therefore, must be the 7-formyl oxygen. When calculating 7-formyl ${ }^{18} \mathrm{O}$ labelling, it was assumed that labelling at the $13^{1}$-oxo group of $\mathrm{Chl} b$ was the same as in Chl $a$. With this assumption, the labelling of the 7-formyl oxygen was 93 and $92 \%$ after 16 and $26 \mathrm{~h}$ incubations, respectively. This is close to the isotopic purity of the precursor ${ }^{18} \mathrm{O}_{2}$ (see section 2) and has important implications (see section 4.1).

In the experiments reported, the photosynthesis inhibitor DCMU was not used to prevent dilution of ${ }^{18} \mathrm{O}_{2}$ by inhibiting ${ }^{16} \mathrm{O}_{2}$ production from $\mathrm{H}_{2}{ }^{16} \mathrm{O}$ in the cell sap. A comparison of the isotope enrichment after 16 and 26 $\mathrm{h}$ showed a decrease of $1-4 \%$ over this period of $10 \mathrm{~h}$ indicating minor dilution by photosynthetically pro-

Table II

${ }^{18} \mathrm{O}$-labeling of chlorophylls during greening

\begin{tabular}{|c|c|c|c|c|c|c|}
\hline \multirow[t]{2}{*}{ Pigment } & \multirow[t]{2}{*}{ Greening time $(\mathrm{h})$} & \multicolumn{3}{|c|}{ Molecular ion intensities (\%) } & \multicolumn{2}{|c|}{ Labeling $^{\mathrm{d}}(\%)$} \\
\hline & & ${ }^{16} \mathrm{O}$ & ${ }^{18} \mathrm{O}$ & ${ }^{18} \mathrm{O}_{2}$ & ${ }^{1 k} \mathrm{O}_{\mathrm{A}}$ & ${ }^{18} \mathrm{O}_{\mathrm{B}}$ \\
\hline \multirow[t]{3}{*}{ Chl $a$} & & $892.5 \mathrm{~m} / \mathrm{z}$ & $894.5 \mathrm{~m} / \mathrm{z}$ & & & \\
\hline & 16 & 32 & 100 & - & 75 & _- \\
\hline & 26 & 39 & 100 & - & 72 & - \\
\hline \multirow[t]{3}{*}{ Phe $a$} & & $870.5 \mathrm{~m} / \mathrm{z}$ & $872.5 \mathrm{~m} / \mathrm{z}$ & & & \\
\hline & 16 & 30 & 100 & & 77 & \\
\hline & 26 & 31 & 100 & - & 76 & - \\
\hline \multicolumn{7}{|c|}{ [7-Hydroxy-methyl]- } \\
\hline \multirow[t]{3}{*}{ Chl $b^{\mathrm{a}}$} & & $9085 \mathrm{~m} / \mathrm{z}$ & $9105 \mathrm{~m} / \mathrm{z}$ & $912.5 \mathrm{~m} / \mathrm{z}$ & & \\
\hline & 16 & 10 & 44 & 100 & $76^{\mathrm{b} . \mathrm{c}}$ & 93 \\
\hline & 26 & 14 & 55 & 100 & $74^{\mathrm{bc}}$ & 92 \\
\hline
\end{tabular}

a [7-hydroxymethyl]-Chl $b$ is only little demetalated under the measuring conditions, therefore the [7-hydroxymethyl]-Phe $b$-derived lons could not be uscd for dctermining the ${ }^{18} \mathrm{O}_{2}$ enrichment. "Median of the labeling or Chl $a / \mathrm{Plie} a$ at the respective times. See text 'According to the mass spectral

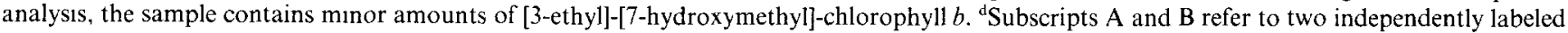
sites. The similar enrichment of site $\mathrm{A}$ in $\mathrm{Chl} a$, Phe $a$ and the $\mathrm{Chl} b$-derivative was the basis for assigning it to the $13^{\prime}$-oxygen, then site $\mathrm{B}$ is the $7^{1}$-oxygen. 


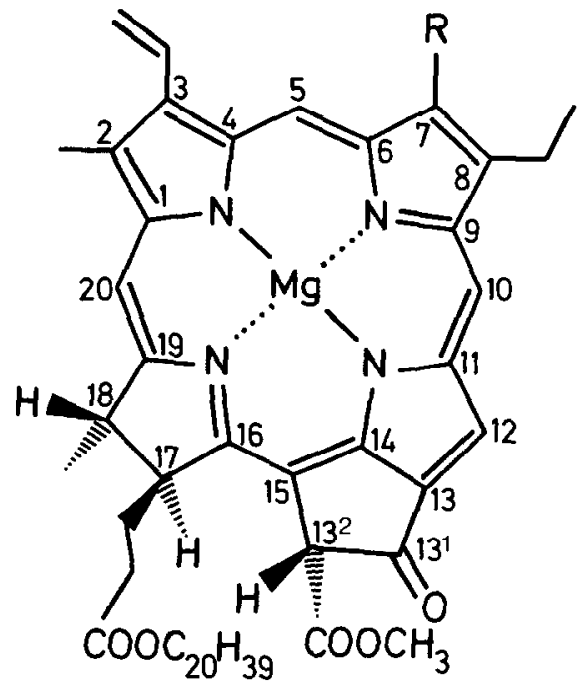

$\begin{array}{ll}\text { Chl orophyll a } & \mathrm{R}-\mathrm{CH}_{3} \\ \text { Chl orophyll b } & \mathrm{R}=\mathrm{CHO} \\ \text { [7-hydroxymethyl] -Chl orophyll b } & \mathrm{R}-\mathrm{CH}_{2} \mathrm{OH}\end{array}$

Fig. 1.

duced ${ }^{16} \mathrm{O}_{2}$. Assuming rapid equilibration of the photosynthetically produced ${ }^{16} \mathrm{O}_{2}$ with the ${ }^{18} \mathrm{O}_{2}$, this $1-4 \%$ decrease in isotope enrichment corresponds to production of aboul $0.5-2.0 \mathrm{ml}$ of ${ }^{16} \mathrm{O}_{2}$ per $50 \mathrm{ml}$ Thunberg tube over the $10 \mathrm{~h}$ period. It has been shown that $\mathrm{C}_{4}$ plants, when photosynthesizing maximally, cvolve 0.07 $\mu \mathrm{mol}$ of $\mathrm{O}_{2}$ per $\mu \mathrm{E}$ absorbed [10]. Thus three leaves with a total area of $25 \mathrm{~cm}^{2}$ in a Thunberg tube would produce $8.5 \mathrm{ml}$ of ${ }^{16} \mathrm{O}_{2}$ in $10 \mathrm{~h}$ at $60 \mu \mathrm{E} \cdot \mathrm{m}^{-2} \cdot \mathrm{s}^{-1}$. However, after $26 \mathrm{~h}$ in the light the leaves are not fully greened and there is considerable self shading in the Thunberg tube. Also, there is a significant lag in the development of $\mathrm{O}_{2}$-evolving activity in greening leaves [11]. Thus formation of $0.5-2.0 \mathrm{ml}$ of ${ }^{16} \mathrm{O}_{2}$ over $10 \mathrm{~h}$ in this experiment is not unreasonable.

\section{DISCUSSION}

In designing the experiment several critical points were considered including the greening conditions. Earlier experiments conducted in closed Thunberg tubes showed that pure ${ }^{16} \mathrm{O}_{2}$ inhibited greening by about $50 \%$ relative to greening in open tubes under normal atmospheric conditions. Because the ${ }^{18} \mathrm{O}_{2}$ studies were also done in closed Thunberg tubes, an atmosphere of approximately $70 \%{ }^{18} \mathrm{O}_{2}$ and $30 \% \mathrm{~N}_{2}$ was chosen since there was little or no inhibition of chlorophyll biosynthesis under these conditions.

Briefly mentioned already, another experimental design consideration was the possible exchange of the formyl oxygen by reversible gem-diol formation. Assuming no isotopic effect, this would dilute the label
$50 \%$ for every turnover. To overcome this problem, the 7-formyl was reduced to a 7-hydroxymethyl-group with $\mathrm{NaBH}_{4}$ in methanol during extraction. This reduction, however, imposed the very considerable experimental difficulty of finding a method to inhibit the concomitant reduction of the 3-vinyl group of $\mathrm{Chl} b$, which unexpectedly occurred in crude methanol extracts of leaves. We found that this reduction, which produces [3-ethyl]-[7hydroxymethyl]-Chl $b$, is inhibited by 7-hydroxyquinoline: this is the subject of a separate publication. The higher ${ }^{18} \mathrm{O}$ enrichment of the 7 -formyl group relative to the $13^{1}$-oxo group indicates that this isotope loss is efficiently inhibited by this reductive extraction procedure. The high incorporation of isotope from ${ }^{18} \mathrm{O}_{2}$ into the formyl group of $\mathrm{Chl} b$ also suggests that reversible gemdiol formation during the long $26 \mathrm{~h}$ greening period in the presence of $\mathrm{H}_{2}{ }^{16} \mathrm{O}$ in the cell sap is slow in the hydrophobic environment of the thylakoid membranes.

Recent work with a Chlorella vulgaris mutant [3], showed comparable ${ }^{18} \mathrm{O}$ enrichment of the $13^{1}$-oxo group of Chl $a$ but enrichment of the 7-formyl-group oxygen was approximately half of that demonstrated here. This indicates that rapid extraction of $\mathrm{Chl} b$ at low temperature, which was the only precaution against this isotope exchange used in the algal study, is less effective than the reductive extraction procedure discussed above.

\subsection{Concluding remarks}

In summary, it has been shown that the 7-formyl oxygen of $\mathrm{Chl} b$ is derived from molecular oxygen and that ${ }^{18} \mathrm{O}$-labelling in excess of $90 \%$ can be achieved by careful optimization of the greening conditions and the extraction procedure. The enrichment achieved is close to the isotopic purity of $99.5 \%$ of the precursor ${ }^{18} \mathrm{O}_{2}$ (see section 2). This very small isotopic dilution suggests a single oxygenase pathway for formyl group formation and unequivocally demonstrates that molecular oxygen is the sole precursor of the formyl oxygen. Since monooxygenases generally yield alcohol as products, either a single enzyme [12] with unusual properties leading directly to a carbonyl group is required or an additional dehydrogenase.

Acknowledgements One of us (R.J.P.) thanks the Deutscher Akademischer Austauschdienst (DAAD) for financial support during his visit to the Botanısches Institut der Unıversität, München, to complete this work. This work was also in part supported by the Deutsche Forschungsgemeinschaft (SFB 143, Projekt A9) and the CSIRO-Division of Plant Industry, Canberra, Australia.

\section{REFERENCES}

[1] Rüdiger, W. and Schoch, S. (1988) in: Plant pigments, (Goodwin, T.W., Ed.) pp. 1-59, Academic Press, London.

12] Beale, S.I. and Welnstein. J.D. (1991) in: Biosynthesis of tetrapyrroles, (Jordan, P.M., Ed.) pp. 155-236.

[3] Schneegurt, M.A. and Beale, S.I. (1992) Biochemistry 31, 11677 11683. 
[4] Sato, N and Murata, N. (1978) Biochım. Biophys. Acta 501, $103-111$.

[5] Klein, O. and Porra. R.J. (1982) Hoppe-Seylers Z Physiol. Chem. 363, 551-562.

[6] Porra, R.J., Klein, O. and Wright. P.E. (1983) Eur. J. Biochem. 130. 509-516.

[7] Naylor, S., Hunter, C.A., Cowan, J.A., Lamb, J.H. and Sanders. J.K.M. (1990) J. Am. Chem. Soc. 112, 6507-6514.

[8] Walker, C.J., Mansfield, K.E., Smith, K.M. and Castelfranco, P.A. (1989) Biochem. J. 257, 599-602
[9] Nashrulhaq-Boyce, A., Griffiths, W.T. and Jones. O.T G. (1987) Biochem. J. 243, 23-29.

[10] Björkman. O. and Dennig. B. (1987) Planta 170, 489-504.

[11] Hennigsen, K.W. and Boardman, N.K. (1973) Plant Physiol. 51, $1117-1126$

[12] Chunaev, A.S , Mirnaya, O N., Maslov, V.G. and Boschettı, A. (1991) Photosynthetica 25, 291-301. 